\title{
Liquid composite moulding of fibre nanocomposites
}

\section{Lekakou*, A. Hearn, A. K. Murugesh and B. Le Page}

Two liquid composite moulding techniques have been investigated in this study, resin transfer moulding (RTM) and resin infusion under flexible tool (RIFT) for the processing of glass fabricepoxy laminates with 5\% nanoaggregates of silica nanoparticles in the epoxy matrix. It has been found that the high fibre fraction reinforcement $\left(V_{f}=0.50\right)$ filters the silica nanoaggregates resulting in stopping the in plane resin infiltration in RTM right at the beginning of the filling stage. Laminates of lower fibre fraction $\left(V_{f}=0.40\right)$ were produced successfully by RIFT. Dynamic mechanical thermal analysis (DMTA) and three point bend tests showed that fibre-silica-epoxy composites, processed by RIFT, had higher elastic shear modulus and interlaminar shear strength than conventional fibre-epoxy composites manufactured by the same RIFT process.

Keywords: Nanocomposites, Liquid composite moulding, RTM, RIFT

\section{Introduction}

Thermoset matrices in fibre reinforced polymers are often brittle and a number of routes have been tried for improving their toughness. One way of improvement is to create a three phase composite material, by including another reinforcing dispersed phase in the polymer matrix in the form of rigid particles, ${ }^{1-3}$ among others, for example. In this case, it has been suggested ${ }^{4}$ that the particles are well dispersed at a critical distance apart so that they allow for a polymer shell of sufficient thickness around each particle that interacts with the particle surface and defines the properties of the particle/polymer interface which might differ from those of the bulk polymer matrix. Nanocomposites with well dispersed nanoparticles have a very large surface area of nanoparticles and, as a result, a large amount of interfacial material between each nanoparticle and the bulk polymer matrix.

Nanoparticles have been reported to benefit polymers in various ways, including retaining transparency. Clay nanocomposites have been under investigation to improve certain polymer properties, such as thermal stability, ${ }^{5}$ fire retardancy, ${ }^{6}$ flexural modulus and strength and toughness, ${ }^{5,7}$ barrier properties, ${ }^{7-9}$ which might improve hydrothermal aging, ${ }^{9}$ and lower shrinkage. ${ }^{10}$ Silica nanocomposites have been reported to display increased mechanical properties ${ }^{11,12}$ such as modulus, tensile, flexural and impact strength up to a certain silica content (e.g. $2 \cdot 5 \%)^{13}$ and decreased mechanical properties thereafter, improved fracture toughness $^{14}$ and better thermal stability. ${ }^{15,16}$

Centre for Materials, Surfaces and Structural Systems, School of Engineering, University of Surrey, Guildford, Surrey GU2 7XH, UK

*Corresponding author, email C.Lekakou@surrey.ac.uk
Hybrid composites including fibre reinforcement in a polymer matrix with dispersed nanoparticles have been the subject of several recent studies where it has been reported that the nanoparticle-fibre composites, when compared with the corresponding fibre composites, displayed higher in plane shear strength (glass fibreorganoclay-epoxy composites ${ }^{17}$ ), increased interlaminar shear strength, flexural strength, flexural modulus and fracture toughness (glass fibre-clay-vinyl ester composites, ${ }^{5}$ glass fibre-clay-epoxy composites, ${ }^{18}$ carbon fibre-clay-epoxy composites, ${ }^{19}$ glass fibre-silica-epoxy composites $^{11}$ ) and better thermal properties. ${ }^{5,18}$

However, there are no studies on the processability of such composites, especially at relatively high fibre content. The vacuum hand lay up process has been used in some studies ${ }^{17,20}$ as it is not only simple but possibly also because it involves impregnation of the nanoresin system only through the short path of the thickness of the laminate. Resin transfer moulding has been used ${ }^{21}$ for very low content, $17 \%$, of short fibres where even clay clusters of $1.5 \mathrm{~mm}$ impregnated the fibre mat successfully in radial outwards flow.

This study starts with an investigation of the processability of an epoxy resin with 5\% nanoaggregates of WACKER silica particles, continues with an exploration of two liquid composite moulding techniques, resin transfer moulding (RTM) and resin infusion under flexible tool (RIFT), to produce fibre nanocomposites, and finally assesses the presence of silica nanoparticles and their effect on matrix dominated properties, namely shear modulus and interlaminar shear strength.

\section{Materials}

The matrix was an epoxy comprising Araldite LY564, based on a bisphenol A epoxy resin with a reactive diluent, and Hardener HY 2954, a cycloaliphatic amine, supplied by Ciba Polymers. Araldite LY564 was mixed 


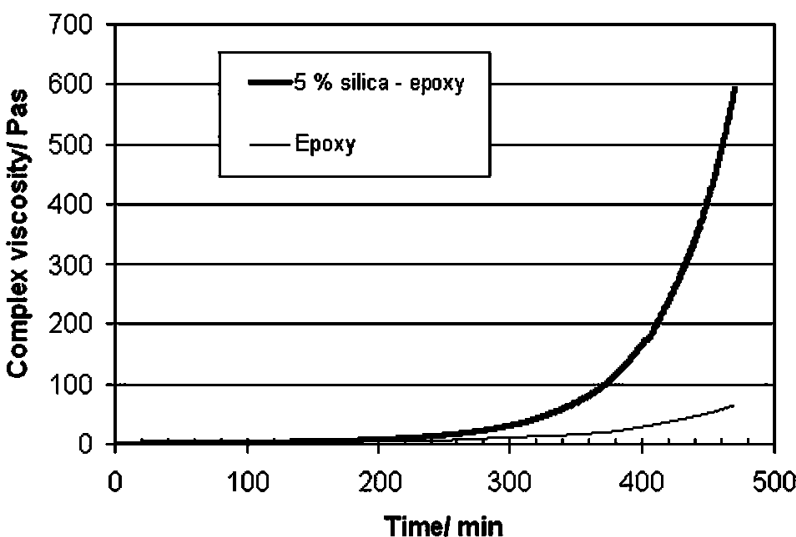

1 Rheological data during curing from DMTA tests at $1.6 \mathrm{~Hz}$ and $20^{\circ} \mathrm{C}$

with WACKER HDK N20 powder in a weight ratio of $100: 7$. After the dispersion of the silica nanoparticles, Hardener HY 2954 was added at an Araldite LY 564 : Hardener HY 2954 weight ratio of $100: 35$ to effect the curing of epoxy, resulting in an epoxy matrix with $\sim 5 \mathrm{wt}-\%$ silica.

WACKER HDK N20 silica powder was used, produced by WACKER SILICONES in the following process: $^{.22}$ primary silica nanoparticles of $\sim 10 \mathrm{~nm}$ are produced during the hydrolysis of trichlorosilane in a hydrogen/oxygen flame at $\sim 1200^{\circ} \mathrm{C}$; in the flame the primary particles fuse into aggregates of about 100 to $500 \mathrm{~nm}$; on cooling, the aggregates flocculate to form agglomerates of about $10-50 \mu \mathrm{m}$, also called tertiary structures. The aggregates consist of primary particles that have fused to form a face to face sintered structure and, hence, cannot be separated by physical means.

An E glass plain woven fabric, Y0212, supplied by Fothergill Engineered Fabrics, was used as the fibre reinforcement in this study in an assembly of several layers, laid up as warp to warp and weft to weft. The fabric had an area density of $0.546 \mathrm{~kg} \mathrm{~m}^{-2}$, a nominal thickness of $0.48 \mathrm{~mm}, 6.7 \mathrm{ends} / 10 \mathrm{~mm}$ and 6.3 picks/ $10 \mathrm{~mm}$ (Ref. 23).

\section{Mixing and rheology of silica-epoxy system}

The silica powder was dispersed in the epoxy resin in a solvent aided procedure to ensure homogeneous mixing, ${ }^{24}$ where ethanol was the solvent employed. A suspension was produced with $10 \mathrm{~g}$ of WACKER HDK N20 powder in $120 \mathrm{~mL}$ ethanol and was sonicated in an ultrasonic bath at room temperature for $30 \mathrm{~min}$ to disperse the silica nanoparticles. Araldite LY564 (140 $\mathrm{mL}$ ) was added to the mixture and the system was mixed mechanically at $1000 \mathrm{rev} \min ^{-1}$ for $30 \mathrm{~min}$. The system was left in an oven at $100^{\circ} \mathrm{C}$ under vacuum for $5 \mathrm{~h}$ to remove the ethanol. The hardener was then added and mixed mechanically at $1000 \mathrm{rev} \mathrm{min}^{-1}$ for $5 \mathrm{~min}$.

Figure 1 displays the complex viscosity of the silicaepoxy curing system monitored in a DMTA test in a Rheometrics RDA II instrument at room temperature and a frequency of $1.6 \mathrm{~Hz}$. It is easily observed that the silica nanoparticles lower the gelling time of the system (324 min for the silica-epoxy system against $440 \mathrm{~min}$ for the pure epoxy system at the same high viscosity value),

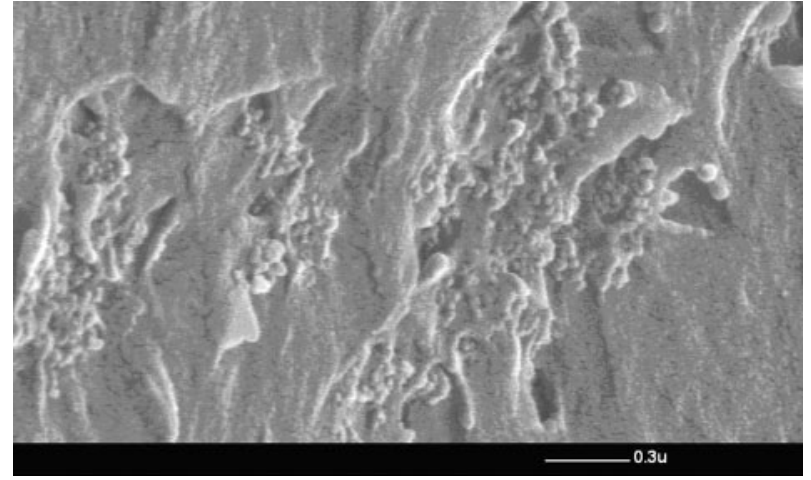

2 lamge (SEM) of $\mathbf{5} \mathrm{wt}$ \% silica-epoxy nanocomposite produced following mixing procedure described in the section on 'Mixing and rheology of silica-epoxy system'

owing to both the locking effect of the rigid silica particles and also the promotion of curing by the silica nanoparticles, as demonstrated in DSC studies. ${ }^{24}$ This means that the process time of the silica-epoxy system for the infiltration stage in liquid composite moulding is going to be much shorter than that of the pure epoxy system.

\section{RTM experiments}

The experiments were carried out in an RTM mould of $350 \times 350 \mathrm{~mm}$ with either side or central injection ${ }^{25,26}$ at $200 \mathrm{kPa}$ injection pressure and room temperature. The 10 layers of woven fabrics were compressed at a fibre fraction $V_{\mathrm{f}}=0.50$ when the mould was closed. The resin was maintained at room temperature to avoid premature gelling, especially taking into account the shorter gel time owing to the presence of nanoparticles in the resin.

In all experiments, the resin flow stopped after a few minutes at a maximum infiltration length of $\sim 100 \mathrm{~mm}$ although the resin had not gelled yet from what it could be deduced about the resin in the flexible inlet tube. The resin was allowed to cure, the laminate was removed from the mould and specimens were sectioned at different distances from the inlet. The specimens characterised in this study were from a moulding produced from a side channel inlet. The specimens were fractured, their fracture surface was gold coated and examined by SEM.

Figure 2 displays an SEM micrograph of the fracture surface of a $5 \%$ silica-epoxy nanocomposite (without fibre reinforcement) where the silica-epoxy system was simply left to cure. The surface consists of features of $50-100 \mathrm{~nm}$ that have been attributed ${ }^{24}$ to well dispersed silica nanoparticles which led to such roughness characteristics in the fracture surface.

Figure 3 presents SEM images from different regions of the glass fibre-silica-epoxy specimens produced by RTM. The resin region at $20 \mathrm{~mm}$ from the gate (Fig. $3 a$ ) presents some roughness characteristics, indicating the presence of nanoparticle aggregates, although the features are smoother than those in the silica-epoxy nanocomposite in Fig. 2. However, the resin region at $70 \mathrm{~mm}$ from the gate (Fig. $3 b$ ) seems totally smooth indicating the brittle failure of pure epoxy without nanoparticles. 


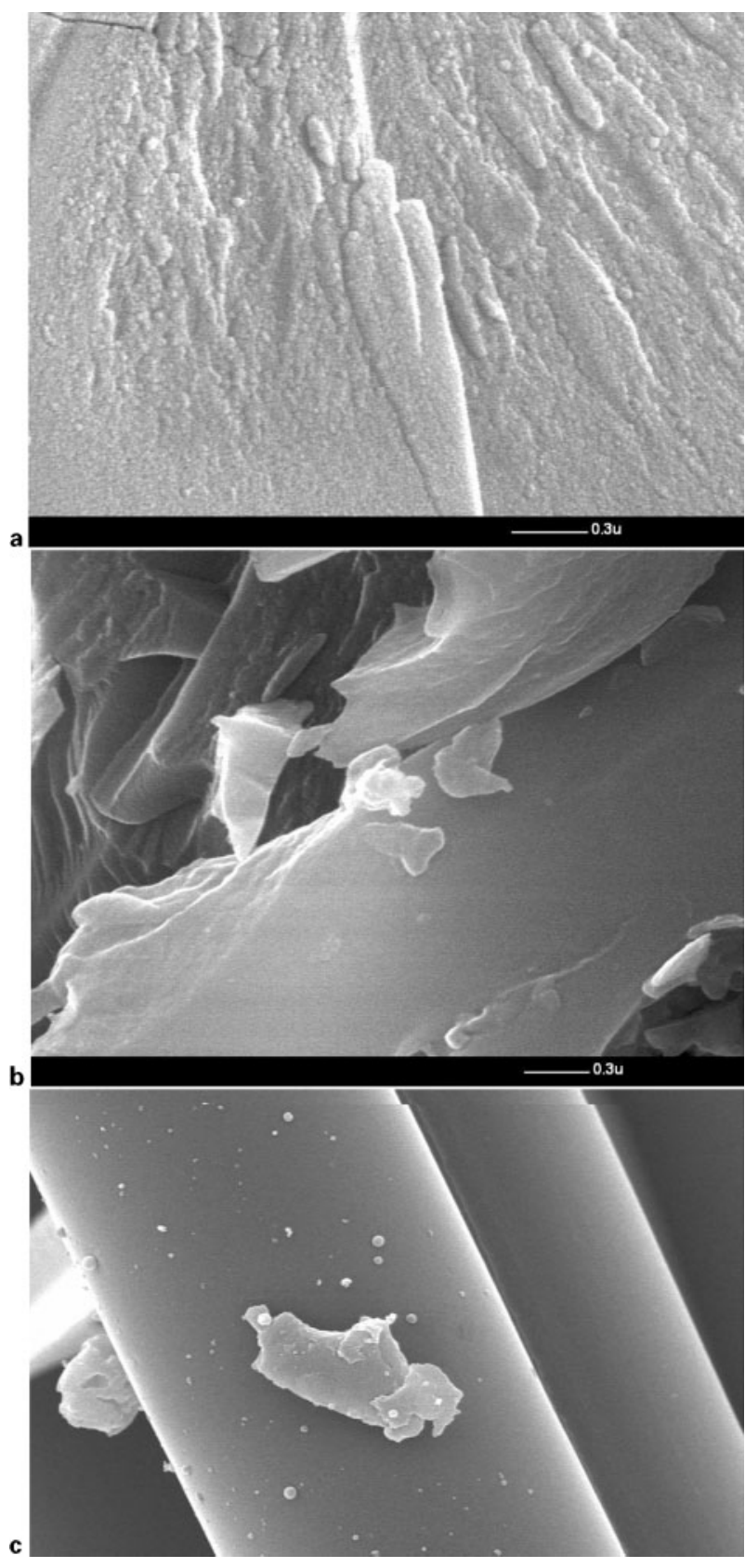

a resin region, $200 \mathrm{~mm}$ away from gate; $b$ resin region, $700 \mathrm{~mm}$ away from gate; $c$ fibres, $700 \mathrm{~mm}$ away from gate

3 Images (SEM) of fracture surface: fibre-silica-epoxy composite produced by RTM at $V_{f}=0.50$

This indicates that the aggregates of silica nanoparticles must have been filtered by the fibre reinforcement in the region of the inlet, as the silica loaded resin flows through the reinforcement. In this case, a 'filter cake' is formed in the porous fibre medium at the inlet and the resin flow stops, as it indeed happened in all RTM experiments.

\section{RIFT experiments}

Nine $220 \times 220 \mathrm{~mm}$ layers of glass fibre fabric Y0212 were laid in the RIFT process. A spring was adjusted at one side of the fibre reinforcement, over the resin inlet, to create a fast resin flow channel as a side inlet (Fig. 4). The whole assembly was covered by a vacuum bag, sealed at the edges and the silica-epoxy system infused the reinforcement under vacuum at room temperature (Fig. 5) and was left to cure at room temperature over a period of 3 days. Fibre composites were produced successfully using either pure epoxy or silica-epoxy resin.

Specimens were sectioned from the above mouldings and subjected to various tests. Since the tensile moduli along the warp and weft directions of the woven reinforcement are expected to be fibre dominated, testing focused on the shear properties, which are expected to be matrix dominated, in order to determine whether the silica nanoparticles would make any difference to these properties. Dynamic mechanical thermal analysis tests were carried out in an RDA II rheometrics instrument at a constant frequency of $1.6 \mathrm{~Hz}$ and a strain of $0.1 \%$ while the temperature was raised at $10 \mathrm{~K} \mathrm{~min}^{-1}$ up to $120^{\circ} \mathrm{C}$. Three point bend tests were performed using an Instron 1175 5500R Universal Testing Machine at a crosshead speed of $0.5 \mathrm{~mm} \mathrm{m^{-1 }}$ with specimen dimensions and design of the test specified so that the specimens would fail under interlaminar shear stress rather than flexure. ${ }^{27}$

\section{Results of characterisation and mechanical testing}

The thickness $H$ of the laminates was measured and the fibre volume fraction $V_{\mathrm{f}}$ was calculated from the relation

$$
V_{\mathrm{f}}=\frac{N \rho_{\mathrm{a}}}{\rho_{\mathrm{f}} H}
$$

where $N$ is the number of fabric layers, $\rho_{\mathrm{a}}$ is the area density of the fabric, $\rho_{\mathrm{f}}$ is the $\mathrm{E}$ glass fibre density $\rho_{\mathrm{f}}=2560 \mathrm{~kg} \mathrm{~m}^{-3}$. All RIFT laminates had a $V_{\mathrm{f}}$ in the range of $0 \cdot 41-0 \cdot 42$, which is relatively low as expected owing to the low consolidation pressure of a nominal vacuum.

Figure 6 displays the elastic shear modulus, $G^{\prime}$, against temperature obtained from DMTA tests for a fibre-pure epoxy sample and a fibre-5\% nanosilica-epoxy sample. This is a matrix dominated property and it can be easily seen that at room temperature the nano-fibre composite has a $G^{\prime}$ of $3 \cdot 1 \mathrm{GPa}$, twice that of the fibre composite without the nanoparticles for which $G^{\prime}=1.6 \mathrm{GPa}$. As the temperature is raised, the specimen with the pure epoxy matrix continues curing hence its shear modulus increases up to $1.7 \mathrm{GPa}$, which is still lower than the shear modulus of the nano-fibre composite. No further curing is observed in the nano-fibre composite. This difference is expected since in a similar temperature ramp in dynamic differential scanning calorimetry (DSC) ${ }^{24}$ during the curing in the processing of the same silica-epoxy system, it was concluded from the exotherms that the 5\% silica-epoxy system cured more than the pure epoxy system. Hence, after the processing stage, the curing continued in the DMTA test for the pure epoxy-fibre composite laminate and showed in the value of $G^{\prime}$ until the glass transition effect started taking over. Overall, the higher shear modulus of the fibre-nanosilica-epoxy composite could be attributed to the locking effect of nanoparticles in the epoxy structure.

In the three point bend tests, the interlaminar shear strength, ILSS, was calculated from the relation ${ }^{27}$

$$
I L S S=\frac{0 \cdot 75 P_{\mathrm{B}}}{b H}
$$

where $P_{\mathrm{B}}$ is the maximum load, $b$ is the width and $H$ is 

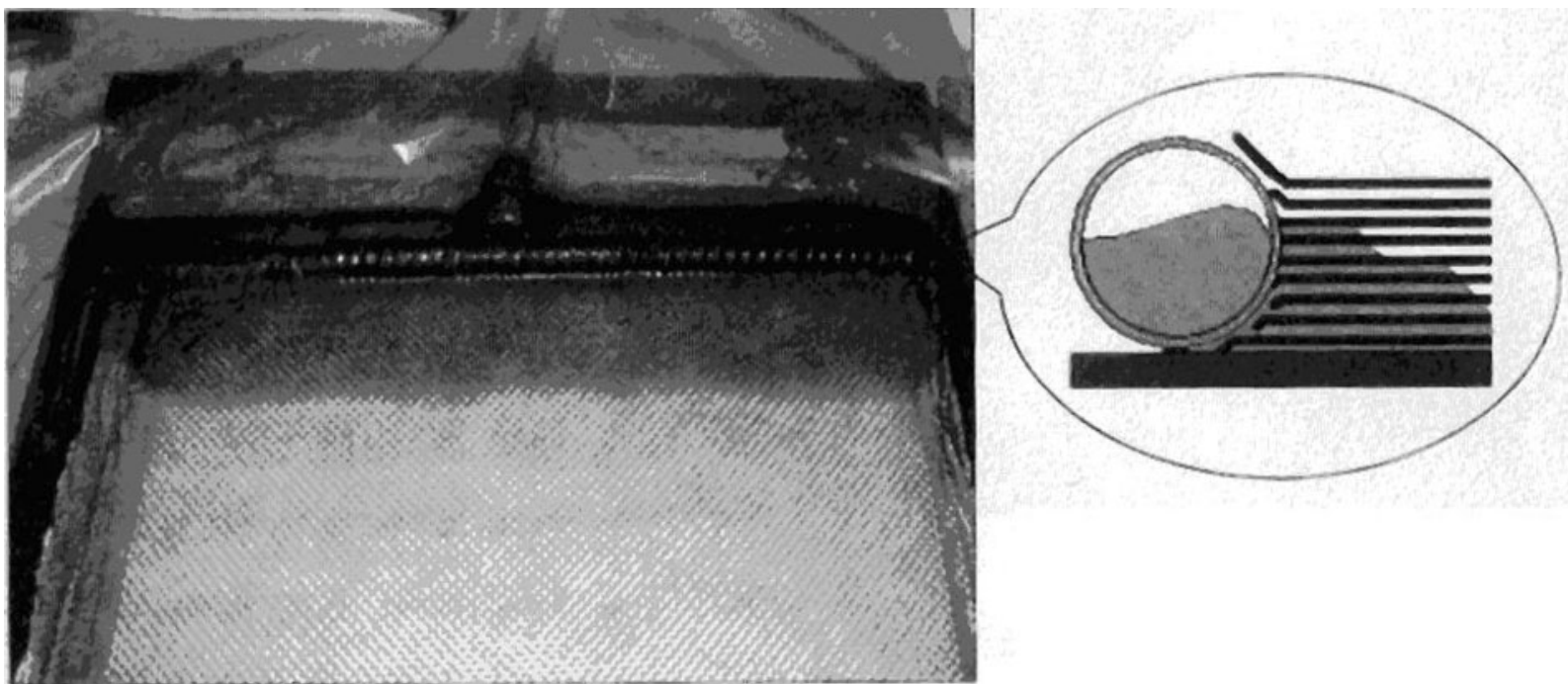

4 Spring arrangement to create channel flow at side inlet in RIFT

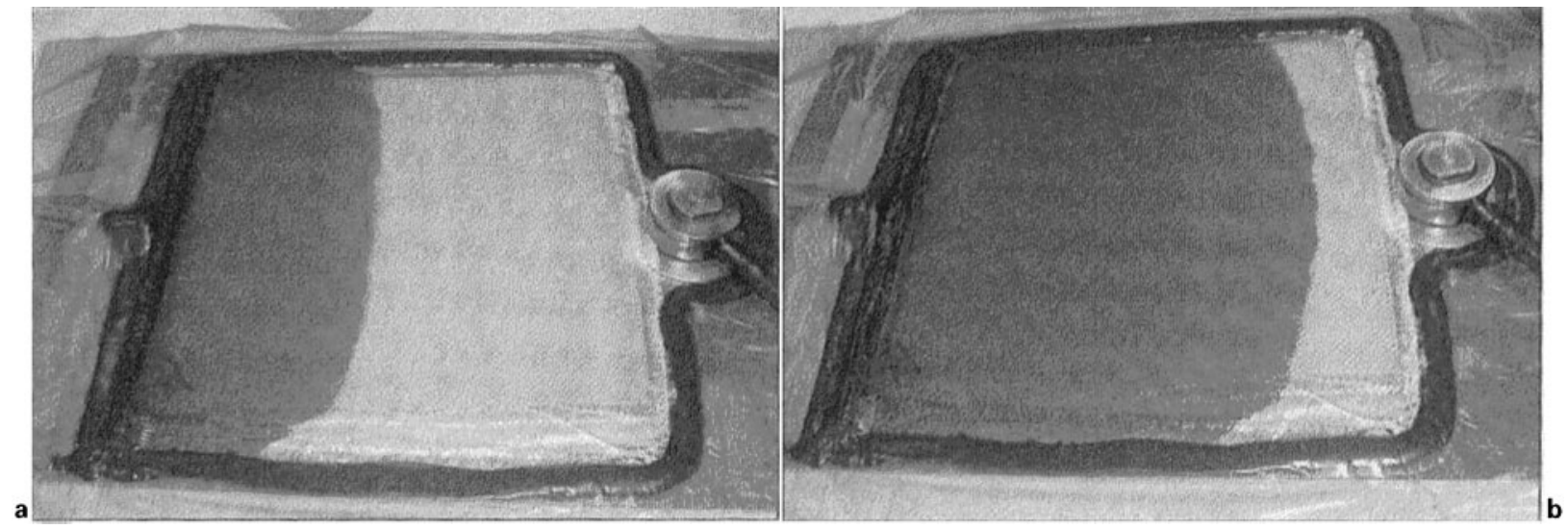

5 Resin infusion under flexible tool processing after a $5 \mathrm{~min}$ and $b 17 \mathrm{~min}$ infiltration time

the thickness of the sample. Table 1 presents the results: the fibre-5\% nanosilica-epoxy composite has a higher ILSS of $6.5 \mathrm{MPa}$ than the conventional fibre-epoxy composite with $I L S S=5 \mathrm{MPa}$. The interlaminar shear strength is clearly a matrix dependent property and a higher $V_{\mathrm{f}}$ reduces $I L S S$ in both types of composites.

\section{Conclusions}

Rheology DMTA tests in this study and DSC tests in a previous study $^{24}$ showed that silica nanoparticles

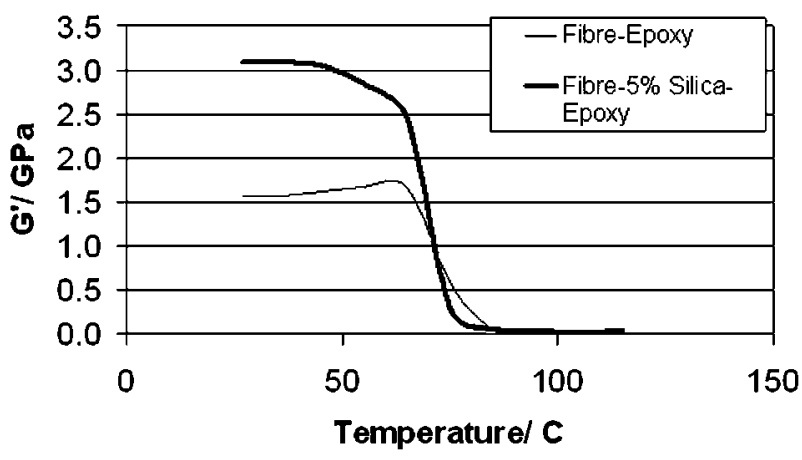

6 Dynamic mechanical thermal analysis tests of composite specimens produced by RIFT; temperature ramp at $10 \mathrm{~K} \mathrm{~min}^{-1}$ at frequency of $1.6 \mathrm{~Hz}$ and strain of $0.1 \%$ promote the curing of epoxies and accelerate gelling. As a result, the mixture needs to be processed at lower temperatures in liquid composite moulding processes to extend the infiltration time.

Two liquid composite moulding techniques, RTM and RIFT, were tried in the processing of glass fibre woven fabric-epoxy composites with $5 \%$ nanoaggregates of silica nanoparticles. Infiltration stopped at very short infiltration length in RTM at room temperature without any premature gelling. Scanning electron microscopy studies of specimens at the gate and a little further away from the gate revealed that the fibre reinforcement at $V_{\mathrm{f}}=0.50$ filtered the nanoaggregates of silica nanoparticles resulting in 'cake' formation in the reinforcement at the gate, which stopped the resin flow.

Fibre-5 wt- $\%$ silica-epoxy nanocomposites were produced successfully by RIFT at $V_{\mathrm{f}}=0 \cdot 41-0 \cdot 42$. Since the
Table 1 interlaminar shear strength results from three point bend tests of specimens produced by RIFT

\begin{tabular}{lll}
\hline Material & $\boldsymbol{V}_{\mathbf{f}}$ & ILSS, MPa \\
\hline Fibre-epoxy & $0 \cdot 42$ & $4 \cdot 7$ \\
Fibre-epoxy & 0.41 & $5 \cdot 3$ \\
Fibre-5\% silica-epoxy & 0.42 & $6 \cdot 2$ \\
Fibre-5\% silica-epoxy & 0.41 & $6 \cdot 7$ \\
\hline
\end{tabular}


tensile moduli in the warp and weft fabric directions were expected to be dominated by the fibres, the composites produced were tested for matrix dominated properties: the fibre nanocomposites displayed double elastic shear modulus and increased interlaminar shear strength compared with conventional fibre-epoxy composites of the same $V_{\mathrm{f}}$, produced by the same RIFT process.

\section{References}

1. J. Spanoudakis and R. J. Young: J. Mater. Sci., 1984, 19, 473-486.

2. J. Spanoudakis and R. J. Young: J. Mater. Sci., 1984, 19, 487-496.

3. M. Imanaka, Y. Takeuchi, Y. Nakamura, A. Nishimura and T. Iida: Int. J. Adhes. Adhes., 2001, 21, 389-396.

4. R. N. Rothon and M. Hancock: in 'Particulate-filled composites', (ed. R. Rothon); 1995, Longman Group Ltd.

5. F. Hussain, D. Dean, A. Haque and A. M. Shamsuzzoha: $J . A d v$. Mater., 2005, 37, (1), 16-27.

6. M. Zammarano, M. Franceschi, S. Bellayer, J. W. Gilman and S. Meriani: Polymer, 2005, 46, (22), 9314-9328.

7. W. P. Liu, S. V. Hoa and M. Pugh: Compos. Sci. Technol., 2005, 65, (15-16), 2364-2373.

8. D. P. R. Kint, G. Seeley, M. Gio-Batta and A. N. Burgess: J. Macromol. Sci. Phys., 2005, 44B, (6), 1021-1040.

9. L. Wang, K. Wang, L. Chen, C. B. He, L. Wang and Y. W. Zhang: Polym. Eng. Sci., 2006, 46, (2), 215-221.

10. L. Xu and J. L. Lee: Proc ICCM, 2003, 14

11. Y. P. Zheng, R. C. Ning and Y. Zheng: J. Reinf. Plast. Compos., 2005, 24, (3), 223-233.
12. K. W. Liang, G. Z. Li, H. Toghiani, J. H. Koo and C. U. Pittman: Chem. Mater., 2006, 18, (2), 301-312.

13. P. Singh, A. Kaushik and A. Kirandeep: J. Reinf. Plast. Compos., 2006, 25, (2), 119-140.

14. G. Ragosta, M. Abbate, P. Musto, G. Scarinzi and L. Mascia: Polymer, 2005, 46, (23), 10506-10516.

15. Q. Chen, R. W. Xu, J. Zhang and D. S. Yu: Macromol. Rapid Comm., 2005, 26, (23), 1878-1882.

16. T. M. Lee and C. C. M. Ma: J. Polym. Sci. Part A, Polym. Chem., 2006, 44A, (2), 757-768

17. J. L. Tsai, J. C. Kuo and S. M. Hsu: Proc. Int. Conf. on 'Advanced manufacture' Taipei, China, November-December 2005, 37-42.

18. A. Haque, M. Shamsuzzoha, F. Hussain and D. Dean: J. Compos. Mater., 2003, 37, (20), 1821-1837.

19. H. Miyagawa, R. J. Jurek, A. K. Mohanty, M. Misra and L. T. Drzal: Compos. Part A, Appl. Sci. Manufactur., 2006, 37A, (1), 54 62.

20. X. Kornmann, M. Rees, Y. Thomann, A. Necola, M. Barbezat and R. Thomann: Compos. Sci. Technol., 2005, 65, (14), 2259-2268.

21. L. Aktas, Y. K. Hamidi and M. C. Altan: Plast. Rub. Compos., 2004, 33, (6), 267-272.

22. WACKER: 'HDK N20 Pyrogenic Silica-Fumed Silica', 2004, available at www.wacker.com/internet/webcache/en_US/PTM/ TM/HDK_N20.pdf?ts $=1107437644605$

23. R. A. Saunders, C. Lekakou and M. G. Bader: Compos. Sci. Technol., 1999, 59, (7), 983-993.

24. C. Lekakou, I. Kontodimopoulos, A. K. Murugesh, D. A. Jesson, J. Watts and P. A. Smith: submitted to Polym. Eng. Sci.

25. S. Amico and C. Lekakou: Compos. Sci. Technol., 2004, 61, (13), 1945-1959.

26. E. Heardman, C. Lekakou and M. G. Bader: Compos. Sci. Technol., 2004, 64, (9), 1239-1249.

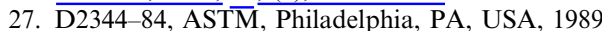

